\title{
SIMBOL KASAB SEBAGAI GAGASAN PENCIPTAAN KARYA TIRAI KALIGRAFI
}

\author{
Widyana Wulandari Z \\ Program Pascasarjana, Penciptaan Seni Kriya \\ Institut Seni Indonesia Padangpanjang \\ Padangpanjang , Sumatra Barat \\ E-mail : widyanawulandari1995@gmail.com
}

\begin{abstract}
Abstrak
Penciptaan karya yang berjudul "Tirai Kaligrafi" mengangkat simbol Kasab sebagai objek penciptaan yang terfokus pada nilai Kasab tentang nasihat kehidupan pemimpin yang diekspresikan melalui seni kaligrafi bersumber dari Al-Qur'an. Kasab adalah benda adat milik masyarakat Aceh Selatan yang digunakan dalam setiap pelaksanaan upacara adat salah satunya pernikahan. Metode penciptaan karya ini melalui beberapa tahap. Tahap eksplorasi, eksperimen, perenungan dan pembentukan. Bahan dasar yang digunakan yaitu kayu surian. Pemilihan medium kayu yang digunakan memiliki kepadatan agar dapat diukir menggunakan mesin Scrool Jigsaw. Teknik pengerjaan yang digunakan yaitu teknik ukir kerawang. Tenik finishing menggunakan cat hitam, emas dan clear. Karya yang diciptakan berjumlah lima item, dengan rupa dua dimensi. Visualisasi karya merupakan ekspresi kaligrafi yang menjadi ornamen pengisi memenuhi bidang lidah-lidah. Berdasarkan karya seni yang diciptakan bertujuan sebagai dakwah penekanan bentuk lebih mengutamakan kejelasan bentuk seni kaligrafi.
\end{abstract}

Kata Kunci: Kasab; Seni Kaligrafi; Konservasi; Dakwah

\begin{abstract}
The creation of the work entitled "Curtain Calligraphy" raised the Kasab symbol as the object of the invention, which focused on Kasab's values about the advice of a leader's life, which was expressed through calligraphy art sourced from the Qur'an. Kasab is a traditional object belonging to the people of South Aceh used in every implementation of conventional ceremonies, one of which is marriage. Creating this work goes through several stagesexploration, experimentation, reflection, and formation. The primary material used is Surian wood. The selection of the wood medium used has a density to be carved using a Scroll Jigsaw machine. The technique used is the filigree carving technique. The finishing technique uses black, gold, and transparent paint. There are five items created with a two-dimensional appearance. The visualization of the work is expression calligraphy becomes an ornament to fill the fields of the tongue. Based on the work of art created to proselytize, emphasis is placed on the clarity of calligraphy art.
\end{abstract}

Keywords: Kasab; Calligraphy Art; Conservation; Da'wah

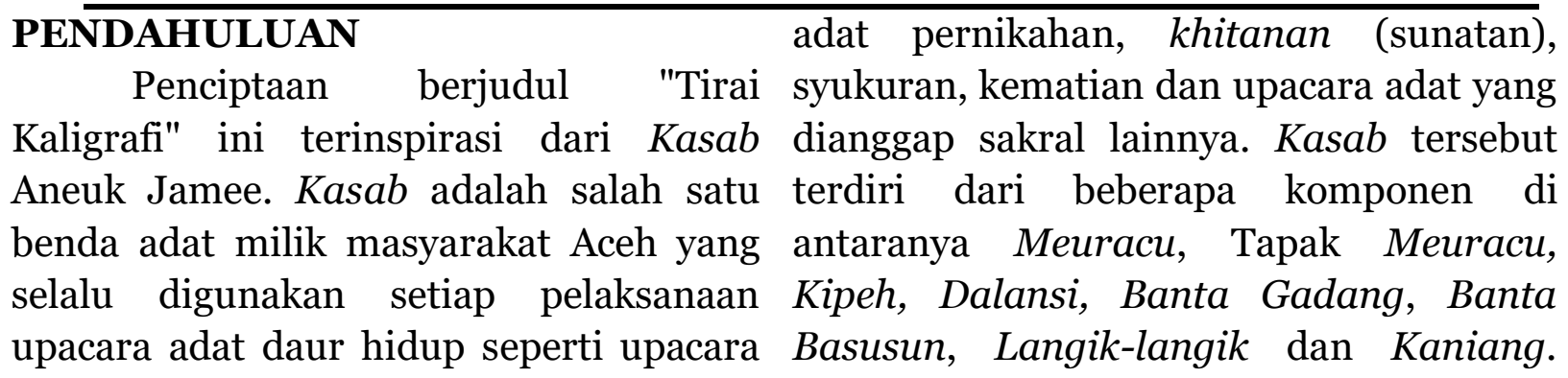


Masing-masing komponen tersebut membuat banyak orang sakit hati (lidah memiliki makna filosofi kehidupan. Salah runcing). Maka dapat digaris bawahi pesan satunya komponen yang ada pada Kasab Kaniang.

Secara harfiah Kaniang artinya kening atau dahi. Kening merupakan bagian paling atas bagian tubuh yang terletak dikepala. Kepala sering di interpretasi sebagai simbol dengan letak pemikiran yang sangat berpengaruh bagi anggota tubuh lainnya. Baik sumber pemikiran, maka baik juga yang akan terealisasi oleh tubuh. Oleh karena itu komponen Kasab dalam hiasan ruangan selalu disusun pada bagian teratas.

Terdapat tiga bagian komponen Kaniang yaitu; pertama, pada bagian paling atas ini melambangkan raja. Bagian ini terdapat motif pucuk rebung, yang bermakna pucuk pemimpin. Kemudian ada motif daun kacang yang panjang menjalar melilit yang bermakna dengan kehidupan manusia yang terus bergerak maju. Kemudian bermotif Bunga Situnjung yang mana dalam kepercayaan masyarakat suku Aceh Selatan memaknai motif ini sebagai keagungan budi nurani masyarakat Aceh Selatan. Berikut bagian kedua terdapat simbol berbentuk lidah, ada dua bentuk lidah yaitu bulat dan runcing. Lidah-lidah ini menyimbolkan sebagai lidah-lidah kepemimpinan. Lidah runcing melambangkan lidah perempuan, yang bulat melambangkan lidah laki-laki.

$$
\text { Jika dikaitkan dalam }
$$

kepemimpinan, dapat dimaknai perdamaian dan persatuan merupakan hal terpenting dalam kehidupan bermasyarakat. Kendati lidah tak bertulang, tetapi kata-kata tanpa terjaga juga tajam (lidah runcing) dapat memicu perpecahan. Maka dari itu seorang pemimpin harus pandai menjaga lidah (lidah bulat) untuk terjaga dari peluang dan nasehat positif yang dapat dijadikan ide peciptaan karya kriya kayu. Yaitu menyampaikan nasehat tentang seorang pemimpin yang berkewajiban menjaga perdamaian dan kesatuan masyarakatnya dengan menjaga lisan dari penyampaian hal-hal yang tidak baik. Telah kita yakini juga bahwa dalam pandangan dan ajaran Agama Islam, Allah Subhanahu Wata'ala memerintahkan manusia untuk menjadi pribadi manusia yang santun dan berakhklaqul karimah, seperti yang telah dicontohkan oleh Rasulullah Salallahu 'Alaihi Wasallam. Berdasarkan firman Allah pada Surah Al-Ahdzab ayat 21 telah ada suri tauladan yang dapat di tauladani oleh manusia dalam memimpin sebuah kaum.

Maka dari penjelasan di atas timbullah suatu ide penciptaan kriya seni tentang nasihat nilai kehidupan dan kepemimpinan kedalam bentuk ukiran kaligrafi. Melalui seni, dakwah dapat disampaikan dan disebarkan kekhalayak dalam wujud yang dapat diterima masyarakat dan syariat, salah satu seni rupa Islam tersebut adalah seni kaligrafi. Kaligrafi atau seni tulis indah adalah suatu jenis tulisan yang bersumber dari tulisan Arab. Menurut bahasa Arab disebut Khath. Yudoseputro mengatakan "...dalam kaligrafi Arab, kata-kata disusun menjadi kalimat yang bersumber pada ayat-ayat dari Al-Qur'an atau Hadith" (1986:115). Kalimat yang dikutip mengandung nasihat tentang kehidupan maupun beragama yang diperkuat oleh dalil. Dalil ini nanti yang akan diaplikasikan kedalam simbol Kasab. Kaligrafi merupakan salah satu ilmu seni yang turun temurun sejak zaman Nabi Muhammad Salallahu 'Alaihi Wassalam. buku Kaligrafi Arab Dengan 
Bacaan Huruf Latin dan Artinya yang menjadi motif pengisi pada simbol mengatakan "sebagian besar kaligrafi Kasab.

adalah cuplikan ayat-ayat atau surahsurah dar Al-Quran serta hadis-hadis dan makolah".

Kaligrafi tersebut menjadi pengisi pada simbol Kasab. Pengisi pada simbol tersebut menjadi ornamen kaligrafi. Penciptaan ini bertujuan sebagai media untuk menyampaikan dakwah kepada masyarakat melalui kaligrafi ayat AlQur'an tentang nasihat kehidupan yang berlandaskan syariat. Berdasarkan tujuan di atas konsep dakwah yang ingin disampaikan adalah tentang kepemimpinan, sesuai dengan komponen Kasab yang dijadikan acuan yaitu lidahlidah

\section{HASIL DAN PEMBAHASAN}

\section{Karya 1}

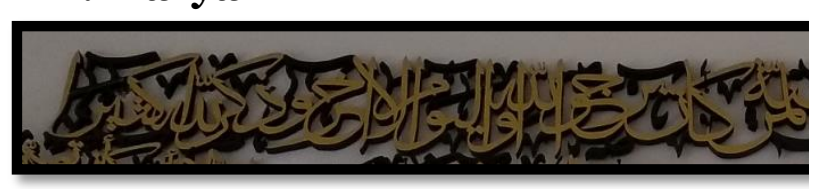

Gambar "Suri Tauladan"

(Foto: Widyana Wulandari Z, 2019)

Konsep Islam tentang kepemimpinan sudah ideal seperti kepemim pinan Nabi Muhammad Shalallahu 'Alaihi Wasallam yang seharusnya dapat menjadi contoh dan panutan.

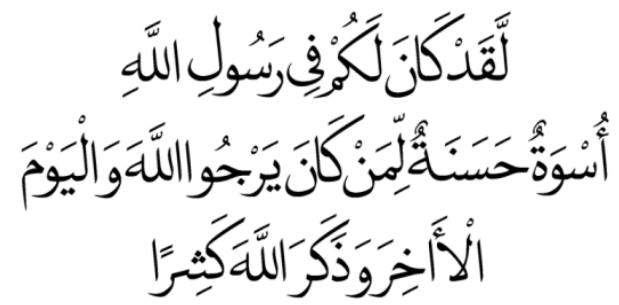

Desain tersebut berangkat dari Kasab berbentuk persegi terletak paling atas yang merepresentasikan sosok pemimpin. Kaligrafi dari Q.S Al-Ahdzab ayat 21 disusun sedemikian rupa berbentuk persegi. Kaligrafi tersebutlah
Karya ini berukuran $160 \mathrm{~cm}$ x $20 \mathrm{~cm}$. Berbahan dasar full kayu yang menggunakan teknik kerawang. Karya ini diukir menggunakan mesin jigsaw dan pahat. Pada tahap finishing menggunakan cat sempot emas dan plitur.

Empat sifat yang dimiliki Nabi sebagai pemimpin dan pembawa risallah Allah yaitu:
1. Shiddiq ( Jujur)
2. Amanah (Dipercaya)
3. Tabligh (Penyampai yang baik)
4. Fathonah (Cerdas dan Pintar)

Dengan bekal keempat sifat ini, Rasulullah berhasil menyampaikan ajaran Islam dan memperoleh kemenangan atas orang-orang musyrik dan kafir Quraisy.

\section{Karya II}

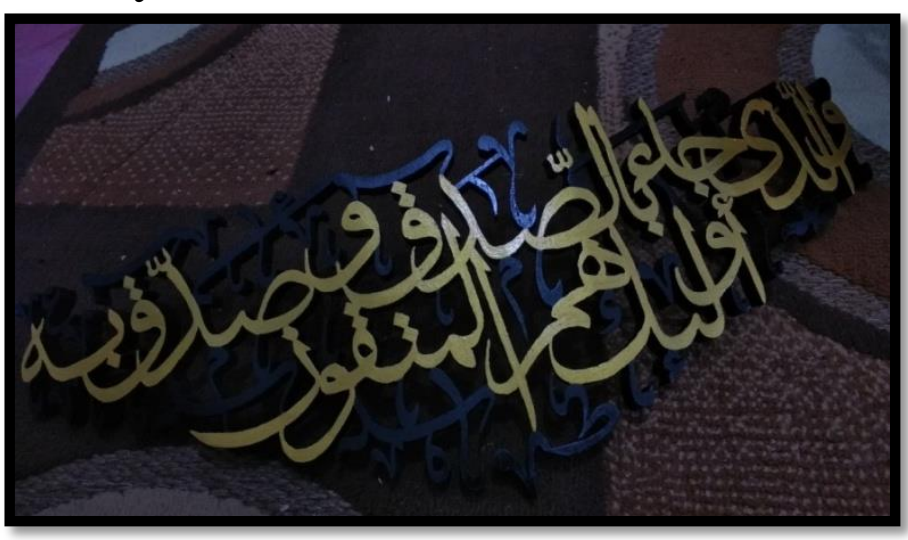

Gambar "Shiddiq"

(Foto: Widyana Wulandari Z, 2019)

Shiddiq adalah sifat dimana seseorang akan selalu berkata dan berperilaku jujur dalam hidupnya. Hal ini merupakan sikap utama yang harus dimiliki seorang pemimpin.

Lawan dari sikap ini adalah kebohongan. Bayangkan bagaimana jika seorang pemimpin terbiasa berbohong? Bagaimana sebuah kehidupan akan sejahtera jika pemimpinnya suka berbohong dan kerap kali menutupi fakta yang harus diketahui masyarakat? Dan hal 
tersebut telah dijelaskankan di dalam Q.S Az-Zumar:33

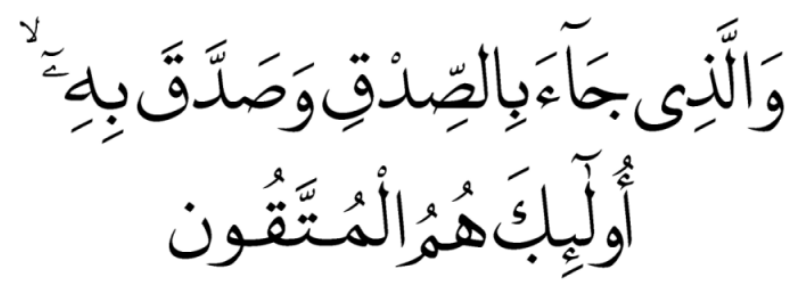

Desain di atas berangkat dari Kasab yang berbentuk lidah-lidah. Kaligrafi dari Q.S Az-Zumar ayat 33 tersebut disusun sedemikian rupa berbentuk lidah-lidah. Kaligrafi tersebutlah yang menjadi motif pengisi pada simbol Kasab tersebut.

Karya ini berukuran $50 \mathrm{~cm} \times 20 \mathrm{~cm}$. Berbahan dasar full kayu yang menggunakan teknik kerawang. Karya ini diukir menggunakan mesin jigsaw dan pahat. Tahap finishing menggunakan cat sempot emas dan bening sebagai pelapis untuk melindungi permukaan cat.

\section{Karya III}

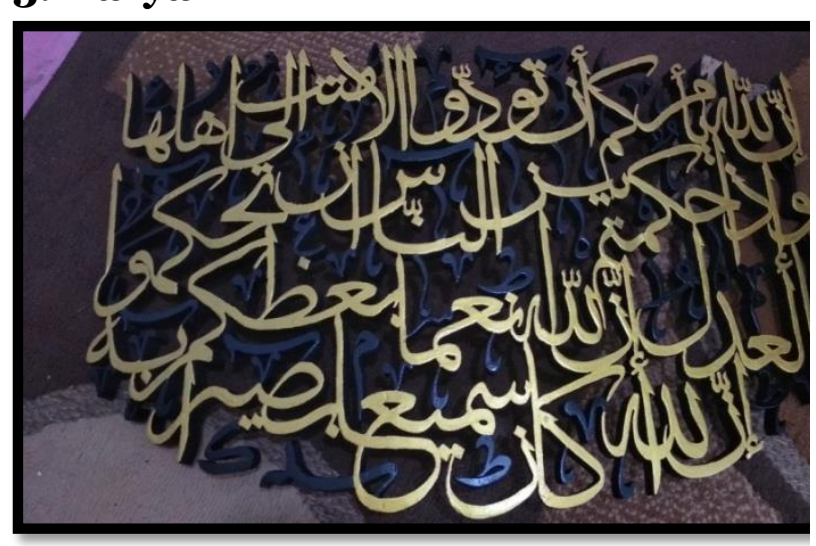

Gambar "Amanah"

(Desain : Widyana Wulandari Z, 2019)

Amanah (Dipercaya) artinya adalah kemampuan untuk menjaga segala sesuatu yang dipercayakan. Kepemimpinan adalah sebuah amanah dan hal ini memiliki makna yang besar, bahwa menjadi pemimpin harus dituntut bertanggungjawab. Tanggungjawab ini bukan hanya kepada rakyat, tetapi juga kepada Allah Subhanahu Wa Ta'ala.

Dan hal tersebut telah disebutkan di dalam Q.S An-Nisa:58

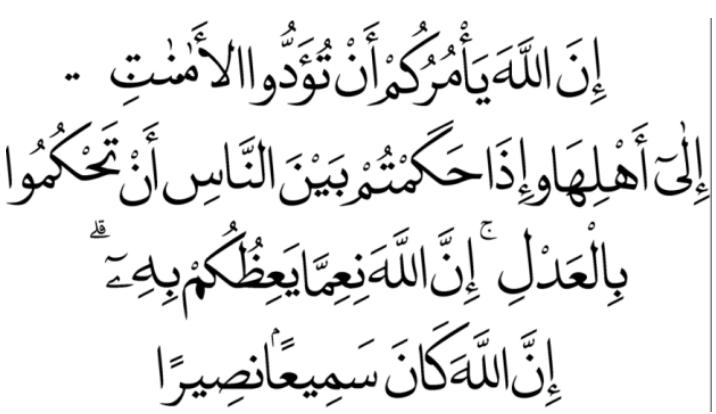

Desain di atas berangkat dari Kasab yang berbentuk lidah-lidah. Kaligrafi dari Q.S An-Nisaa ayat 58 tersebut disusun sedemikian rupa berbentuk lidah-lidah. Kaligrafi tersebutlah yang menjadi motif pengisi pada simbol Kasab tersebut. Karya ini berukuran $50 \mathrm{~cm} \times 40 \mathrm{~cm}$. Berbahan dasar full kayu yang menggunakan teknik kerawang. Karya ini diukir menggunakan mesin jigsaw dan pahat. Pada tahap finishing menggunakan cat sempot emas dan plitur.

\section{Karya IV}

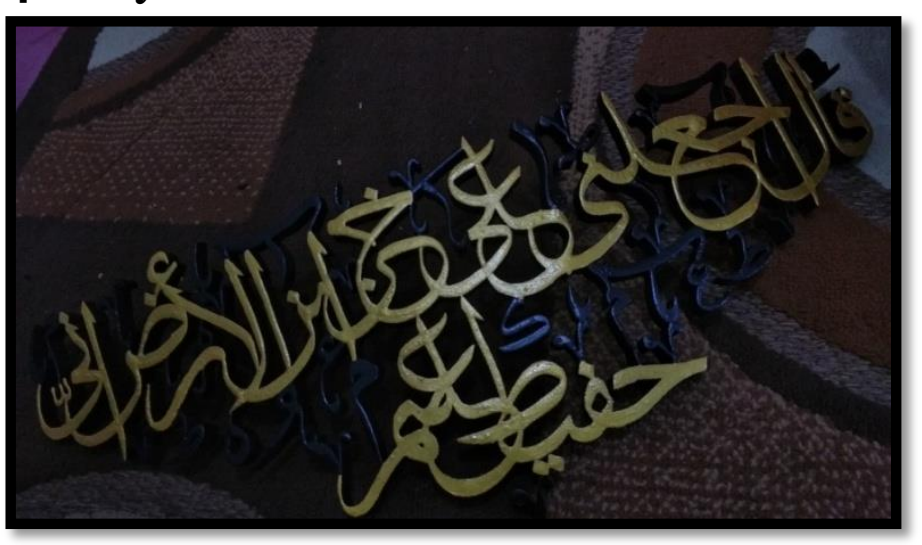

Gambar "Fathonah"

(Desain : Widyana Wulandari Z, 2019)

Fathonah artinya seorang pemimpin haruslah memiliki kecerdasan diatas ratarata masyarakatnya sehingga memiliki kepercayaan diri. Kecerdasan pemimpin akan membantunya dalam memecahkan segala macam persoalan yang terjadi dimasyarakat.

Pemimpin yang cerdas tidak mudah frustasi karena dengan kecerdasannya dia akan mampu mencari solusi. Pemimpin yang cerdas tidak akan membiarkan 
masalah berlangsung lama karena ia selalu dapat menyelesaikan masalah dengan cepat.

Dan hal tersebut telah disebutkan di dalam Q.S Yusuf ayat 55:

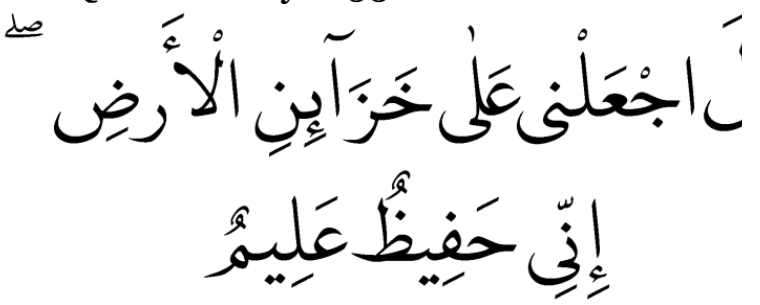

Desain di atas berangkat dari Kasab yang berbentuk lidah-lidah. Kaligrafi dari Q.S Yusuf ayat 55 tersebut disusun sedemikian rupa berbentuk lidah-lidah. Kaligrafi tersebutlah yang menjadi motif pengisi pada simbol Kasab tersebut. Karya ini berukuran $50 \mathrm{~cm} \times 20 \mathrm{~cm}$. Berbahan dasar full kayu yang menggunakan teknik kerawang. Karya ini diukir menggunakan mesin jigsaw dan pahat. Pada tahap finishing menggunakan cat sempot emas dan plitur.

\section{Karya V}

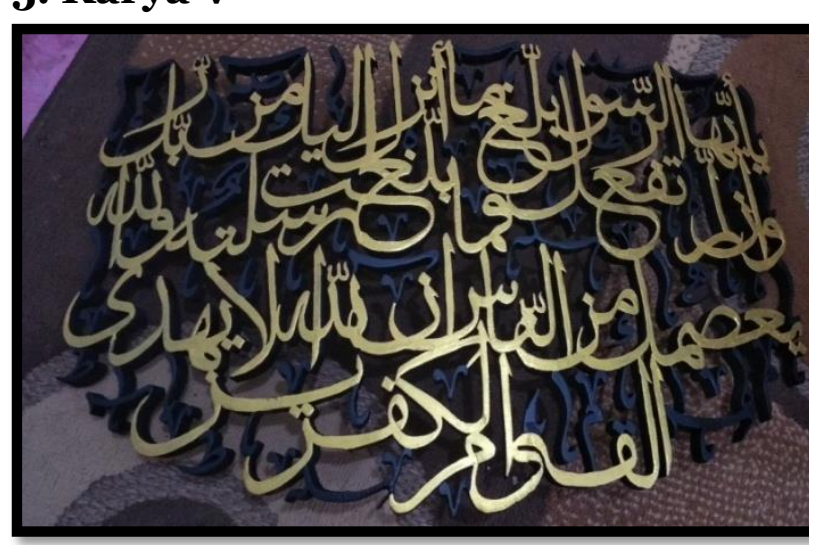

Gambar "Tabligh"

(Desain : Widyana Wulandari Z, 2019)

Tabligh diartikan sifat ini sebagi bentuk penyampaian yang jujur sekaligus bertanggungjawab atas tindakan yang diambilnya. Pemimpin yang tabligh tidak akan menutupi atau melindungi kesalahan-kesalahan atau kemunkaran yang terjadi dalam kepemimpinan. Seorang pemimpin tidak boleh bersifat demikian karena itu merupakan sifat seorang pemimpin yang dzalim.

Hal ini telah disebutkan di dalam Q.S Al-Maidah ayat 67:

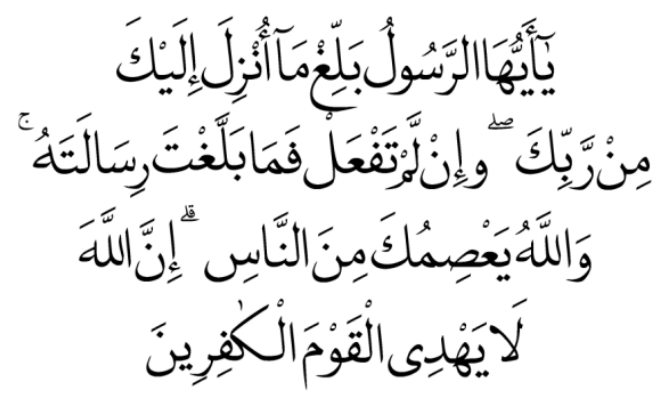

Desain di atas berangkat dari Kasab yang berbentuk lidah-lidah. Kaligrafi dari Q.S Al-Maidah ayat 67 tersebut disusun sedemikian rupa berbentuk lidah-lidah. Kaligrafi tersebutlah yang menjadi motif pengisi pada simbol Kasab tersebut.

Karya ini berukuran $50 \mathrm{~cm} \mathrm{x} 40 \mathrm{~cm}$. Berbahan dasar full kayu yang menggunakan teknik kerawang. Karya ini diukir menggunakan mesin jigsaw dan pahat. Pada tahap finishing menggunakan cat sempot emas dan plitur

\section{Desain Pameran}

Pameran adalah kegiatan akhir dari penciptaan karya. Setelah menciptakan karya, karya tersebut dipamerkan diruang publik untuk memenuhi sasaran tercapai atau tidak perencanaan konsep yang diatur.

Peletakan karya atau display karya sangat penting bagi seorang pencipta karena kualitas karya ditampilkan juga dilihat dari segi pendisplayan karya. Berikut hasil akhir display karya. 


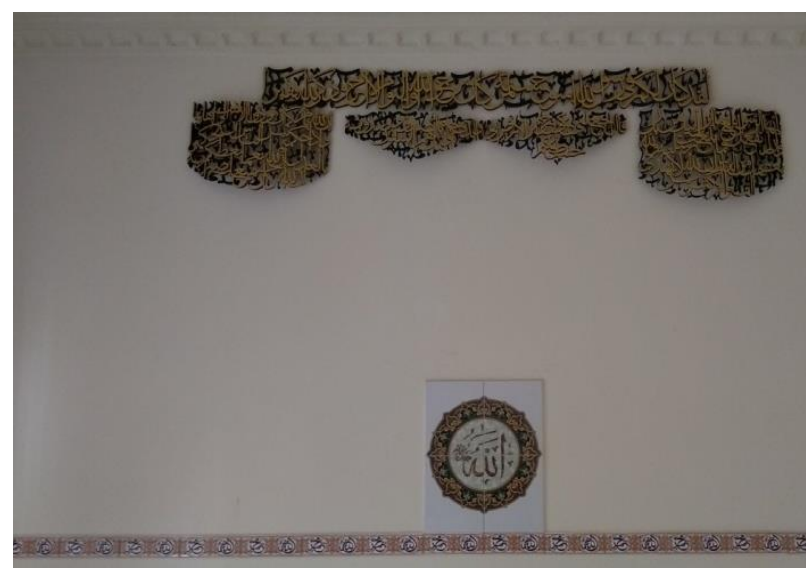

Gambar Display Pameran

(Desain : Widyana Wulandari Z, 2019)

\section{PENUTUP}

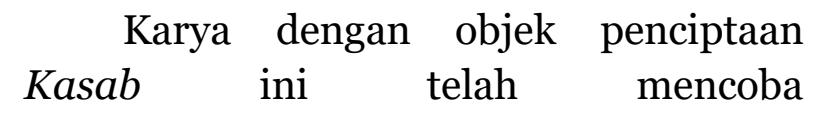
merepresentasikan suatu makna, pesan dan tanda yang mengandung nasihat tentang kepemimpinan ke dalam ornamen kaligrafi. Melalui karya ini masyarakat Aceh khususnya Aceh Selatan dapat memahami makna apa yang terdapat pada Kasab baik dari segi estetika maupun dalam segi agama. Karya ini bertujuan menyampaikan dakwah tentang makna kehidupan dan agama serta syari'at yang mana nasihat dan nilainya secara seni estetika ada pada simbol dan motif Kasab.

Proses pembuatan karya ukir kayu ini ditempuh melalui beberapa tahap sebagai berikut: (a) mendesain pola kaligrafi Arab beserta bidang background pola Kasab pada kertas dengan pengaturan komposisinya. Untuk membuat pola ini menggunakan pensil untuk sket dan menggunakan spidol jika sket sudah jadi sehingga jelas, (b) gambar desain diaplikasikan pada papan kayu (c) mengukir desain pada papan kayu dengan cara digergaji kayu sesuai gambar desain secara global. Setelah itu di mulai tahap ngalusi yaitu membentuk pola gambar secara halus kearah penyempurnaan bentuk yang diinginkan, (d) penghalusan menggunakan amplas pada semua objek karya, (e) langkah terakhir yaitu karya di warna menggunakan cat semprot putih untuk warna dasar, cat gold (emas) untuk warna utama, dan terakhir warna clear (bening) untuk pengkilapan warna.

Hasil karya seni ukir kayu dua dimensional berbentuk pola Kasab dan kaligrafi Arab sebagai ornamen pengisi. Kalimat yang diambil adalah Ayat pertama pada Surat Al-Ikhlas, kalimat Tauhid dan kalimat dzikir takbir, tahmit dan tasbih.

\section{Saran}

Berdasarkan hasil proses berkarya, dapat dikemukakan beberapa saran sebagai berikut:

1. Dalam pembuatan karya seni tak terlepas dari sebuah konsep, sehingga konsep perlu diperhatikan. Ketrampilan juga sangat diperlukan dalam berkarya seni sehingga dibutuhkan latihan - latihan untuk mengasahnya.

2. Karya seni ukir menggunakan mesin scroll merupakan karya seni yang sedikit rumit, sehingga diperlukan kesabaran, ketekunan, ketelitian dan ketrampilan dalam menuangkan ide ke media karya.

3. Untuk lebih memaksimalkan hasil karya, perlu diperhatikan pula alat dan sarana penunjang lainnya yang mendukung dalam pembuatan karya seni ukir kayu ini

\section{DAFTAR PUSTAKA}

Al-Qur'an

Faqih, Abi. 2012. Contoh Kaligrafi Arab Dengan Bacaan Huruf Latin dan Artinya. Surabaya: Apollo Lestari

Guntur, 2004. Ornamen Sebuah Pengantar. Surakarta: P2AI bekerja 
sama dengan STSI Press Surakarta.

Gustami, SP, 2007.Butir-Butir Mutiara

Estetika Timur "Ide Dasar

Penciptaan Seni Kriya Indonesia”. Banda Aceh: Dinas Kebudayaan dan Pariwisata Aceh Bidang Adat dan Nilai Budaya.

Hermaliza, Essi, dkk. 2013. Simbol dan Makna Kasab di Aceh Selatan. Banda Aceh: Balai Pelestarian Nilai Budaya Banda Aceh.

Leigh, Barbara. 1989. Tangan-Tangan Terampil. Jakarta: Penerbit Djambatan.

Sirrajuddin AR, D. 1992. Seni Kaligrafi Islam. Jakarta: Multi Kreasi Singgasana Sustarina, Yelly. 2015. Catatan Pengrajin Kasab. Banda Aceh: Kota Naga.

Yudoseputro, Wiyoso. 1986. Pengantar Seni Rupa Islam Di Indonesia. Bandung: Angkasa.

Yulika, Febri. 2012. Sejarah Perkembangan Seni Islam dan Kesenian dalam Islam Jilid I. ISI Padangpanjang. 